\title{
Investigation of substituent effect of 1-(3,3-diphenylpropyl)-piperidinyl phenylacetamides on CCR5 binding affinity using QSAR and virtual screening techniques
}

\author{
Antreas Afantitis $^{\mathrm{a}, \mathrm{b}}$, Georgia Melagraki ${ }^{\mathrm{a}}$, Haralambos Sarimveis ${ }^{\mathrm{a}, *}$, Panayiotis A. \\ Koutentis $^{\mathrm{c}}$, John Markopoulos ${ }^{\mathrm{d}}$ \& Olga Igglessi-Markopoulou ${ }^{\mathrm{a}}$ \\ ${ }^{a}$ School of Chemical Engineering, National Technical University of Athens, Athens, Greece; ${ }^{b}$ Department of \\ ChemoInformatics, NovaMechanics Ltd, Larnaca, Cyprus; ${ }^{\mathrm{c}}$ Department of Chemistry, University of Cyprus, \\ P.O. Box 20537 1678, Nicosia, Cyprus; ${ }^{\mathrm{d}}$ Department of Chemistry, University of Athens, Athens, Greece
}

Received 1 December 2005; accepted 26 January 2006

(C) Springer 2006

Key words: CCR5, binding affinity, QSAR, virtual screening

\begin{abstract}
Summary
A linear quantitative-structure activity relationship model is developed in this work using Multiple Linear Regression Analysis as applied to a series of 51 1-(3,3-diphenylpropyl)-piperidinyl phenylacetamides derivatives with CCR5 binding affinity. For the selection of the best variables the Elimination SelectionStepwise Regression Method (ES-SWR) is utilized. The predictive ability of the model is evaluated against a set of 13 compounds. Based on the produced QSAR model and an analysis on the domain of its applicability, the effects of various structural modifications on biological activity are investigated. The study leads to a number of guanidine derivatives with significantly improved predicted activities.
\end{abstract}

\section{Introduction}

The chemokine receptor CCR5 is expressed on T-lymphocytes, monocytes, macrophages, dendritic cells, microglia and other cell types [1]. These receptors detect and respond to several chemokines principally "regulated on activation normal T-cell expressed and secreted" (RANTES) and macrophage inflammatory proteins (MIP) MIP- $1 \alpha$ and MIP- $1 \beta$, resulting in the recruitment of cells of the immune system to sites of disease. CCR5 is also co-receptor for HIV-1 and other viruses, enabling these viruses to enter cells. Individuals, who are homozygous for 32-bp deletion in the gene encoding CCR5, whilst otherwise healthy, are strongly protected against infection

\footnotetext{
*To whom correspondence should be addressed. E-mail: hsarimv@central.ntua.gr
}

[2]. Many studies indicate different roles for CCR5 and its ligands in disorders such as rheumatoid arthritis [3], multiple sclerosis [4], transplant rejection [5] and inflammatory bowel disease [6]. These observations suggest that molecules that modulate the CCR5 receptor would have potential benefit in a wide range of diseases.

In the past, several attempts have been made to build QSAR models in the general field of CCR5 binding affinity. Debnath [7] presented predictive pharmacophore models for CCR5 antagonists using piperidine and piperazine derivatives. Song et al. [8] presented a 3D Quantitative Structure Activity Relationship (QSAR) study using piperidine derivatives. Xu et al. [9] using Molecular Docking and 3D QSAR presented a study based on 1-amino-2-phenyl-4-(pipridin-1-yl)butane derivatives. Finally, Roy and Leonard presented two validated QSAR studies using 
substituted benzylpyrazole [10] and 3-(4-benzylpiperidin-1-yl)- $N$-phenylpropylamine [11] derivatives. With the latter derivatives [11] 3D-QSAR and more specifically Molecular Shape Analysis (MSA), Receptor Surface Analysis (RSA) and Molecular Field Analysis (MFA) were applied.

In this work, we selected a series of 51 1-(3, 3-diphenylpropyl)-piperidinyl phenylacetamides amides [1] to investigate their role as CCR5 receptor modulators. Sixty-one physicochemical and topological descriptors were examined in terms of their efficacy to determinate and predict the activity of the investigated derivatives. The descriptors were calculated using Topix (www.lohninger.com/topix.html) and ChemSar which is included in the ChemOffice (CambridgeSoft Corporation) suite of programs. Among them, the most statistically significant descriptors were selected, using a rigorous variable selection method. The result of this study was the development of a new linear QSAR model containing 7 descriptors. In order to validate the proposed methodology, we used two strategies: Y-randomization and external validation using division of the entire data set into training and test sets. Based on the new QSAR model and the detection of its domain of applicability, the effects of various structural modifications on the biological activity were investigated.

\section{Materials and methods}

\section{Data set}

In this QSAR study 52 biological data from Burrows's et al. [1] work were used. The biological activities of these 52 compounds were reported in the same papers [1]. In order to model and predict the specific activity (CCR5 binding affinity), 61 physicochemical constants, topological and structural descriptors (Table 1) were considered as possible input candidates to the model. All the descriptors were calculated using ChemSar and Topix.

\section{Stepwise multiple regression}

The ES-SWR algorithm was used to select the most appropriate descriptors. ES-SWR is a popular stepwise technique [12] that combines
Forward Selection (FS-SWR) and Backward Elimination (BE-SWR). It is essentially a forward selection approach, but at each step it considers the possibility of deleting a variable as in the backward elimination approach, provided that the number of model variables is greater than two. The two basic elements of the ES-SWR method are described below in more details.

\section{Forward selection}

The variable considered for inclusion at any step is the one yielding the largest single degree of freedom $F$-ratio among the variables that are eligible for inclusion. The variable is included only if the corresponding $F$-ratio is larger than a fixed value $F_{\text {in }}$. Consequently, at each step, the $j$ th variable is added to a $k$-size model if

$$
F_{j}=\max _{j}\left(\frac{\mathrm{RSS}_{k}-\mathrm{RSS}_{k+j}}{s_{k+j}^{2}}\right)>F_{\text {in }}
$$

In the above in equality RSS is the residual sum of squares and $s$ is the mean square error. The subscript $k+j$ refers to quantities computed when the $j$ th variable is added to the $k$ variables that are already included in the model.

\section{Backward elimination}

The variable considered for elimination at any step is the one yielding the minimum single degree of freedom $F$-ratio among the variables that are included in the model. The variable is eliminated only if the corresponding $F$-ratio does not exceed a specified value $F_{\text {out. }}$ Consequently, at each step, the $j$ th variable is eliminated from the $k$-size model if

$$
F_{j}=\min _{j}\left(\frac{\mathrm{RSS}_{k-j}-\mathrm{RSS}_{k}}{s_{k}^{2}}\right)<F_{\text {out }}
$$

The subscript $k-j$ refers to quantities computed when the $j$ th variable is eliminated from the $k$ variables that have been included in the model so far.

\section{Cross-validation technique}

The reliability of the proposed method was explored using the cross-validation method. Based on this technique, a number of modified data sets are created by deleting in each case one (LOO, 
Table 1. Physicochemical constants, topological and structural descriptors.

\begin{tabular}{|c|c|c|c|c|c|}
\hline ID & Description & Notation & ID & Description & Notation \\
\hline 1 & Molar Refractivity & MR & 2 & Diameter & Diam \\
\hline 3 & Partition Coefficient (Octanol Water) & $\mathrm{Clog} \mathrm{P}$ & 4 & Molecular Topological Index & TIndx \\
\hline 5 & Principal Moment of Inertia Z & PMIZ & 6 & Number of Rotatable Bonds & NRBo \\
\hline 7 & Principal Moment of Inertia $\mathrm{Y}$ & PMIY & 8 & Polar Surface Area & PSAr \\
\hline 9 & Principal Moment of Inertia X & PMIX & 10 & Radius & Rad \\
\hline 11 & Connolly Accessible Area & SAS & 12 & Shape attribute & ShpA \\
\hline 13 & Connolly Molecular Area & MS & 14 & Shape coefficient & ShpC \\
\hline 15 & Total Energy & TotE & 16 & Sum of Valence Degrees & SVDe \\
\hline 17 & LUMO Energy & LUMO & 18 & Total Connectivity & TCon \\
\hline 19 & HOMO Energy & HOMO & 20 & Total Valence Connectivity & TVCon \\
\hline 21 & Balaban Index & BIndx & 22 & Wiener Index & WIndx \\
\hline 23 & Cluster Count & $\mathrm{ClsC}$ & 24 & Randic 0 & Chio \\
\hline 25 & Randic 1 & Chil & 26 & Randic 2 & Chi2 \\
\hline 27 & Randic 3 & Chi3 & 28 & Randic 4 & Chi4 \\
\hline 29 & Randic Information 0 & ChiInf0 & 30 & Randic Information 1 & ChiInf1 \\
\hline 31 & Randic Information 2 & ChiInf2 & 32 & Randic Information 3 & ChiInf3 \\
\hline 33 & Randic Information 4 & ChiInf4 & 34 & Kier-Hall 0 & $\mathrm{Ki0}$ \\
\hline 35 & Randic Mod & ChiMod & 36 & $\mathrm{Xu} 1$ & $\mathrm{Xu} 1$ \\
\hline 37 & $\mathrm{Xu} 2$ & $\mathrm{Xu} 2$ & 38 & $\mathrm{Xu} 3$ & $\mathrm{Xu} 3$ \\
\hline 39 & Balaban Topological & TopoJ & 40 & Topological Radius & TopoRad \\
\hline 41 & Topological Diameter & TopoDia & 42 & Number of Bramches & NBranch \\
\hline 43 & Number of Rings & Nrings & 44 & WienerDim & WienerDim \\
\hline 45 & Bertz & Bertz & 46 & AtomCompMean & AtomCompMean \\
\hline 47 & AtomCompTot & AtomCompTot & 48 & Zagreb1 & Zagreb1 \\
\hline 49 & Zagreb2 & Zagreb2 & 50 & Quadratic & Quadr \\
\hline 51 & ScHultz & ScHultz & 52 & Kappa1 & Kappa1 \\
\hline 53 & Kappa3 & Kappa3 & 54 & Kappa2 & Kappa2 \\
\hline 55 & Wiener Distance & WienerDistCode & 56 & Wiener Information & InfWiener \\
\hline 57 & DistEqMean & DistEqMean & 58 & DistEqTotal & DistEqTotal \\
\hline 59 & InfMagnitDistTot & InfMagnitDistTot & 60 & Polarity & Polarity \\
\hline 61 & Gordon & Gordon & & & \\
\hline
\end{tabular}

leave one out) or a small group (leave some out) of objects [13-15], thus leading to the development of multiple input-output models. Each model is evaluated, by measuring its accuracy in predicting the responses of the remaining data (the ones that have not been utilized in the development of the model). In particular, the LOO procedure was utilized in this study, where the total number of produced models is equal to the number of available examples. More precisely, a different model is produced by deleting each time one object from the training set. Prediction error sum of squares (PRESS) is a standard index to measure the accuracy of a modeling method based on the cross-validation technique. Using the PRESS and SSY (sum of squares of deviations of the experimental values from their mean) statistics, the $R_{\mathrm{CV}}^{2}$ and $S_{\text {PRESs }}$ values can be easily calculated. The formulae that calculate the aforementioned statistics are presented below (Equations 3 and 4):

$$
R_{\mathrm{CV}}^{2}=1-\frac{\text { PRESS }}{\mathrm{SSY}}=1-\frac{\sum_{i=1}^{n}\left(Y_{\exp }-Y_{\text {pred }}\right)^{2}}{\sum_{i=1}^{n}\left(Y_{\exp }-\bar{Y}\right)^{2}}
$$

$$
S_{\text {PRESS }}=\sqrt{\frac{\text { PRESS }}{n}}
$$




\section{$Y$-randomization test}

This technique ensures the robustness of a QSAR model [16, 17]. The dependent variable vector (biological action) is randomly shuffled and a new QSAR model is developed using the original independent variable matrix. The new QSAR models (after several repetitions) are expected to have low $R^{2}$ and $R_{\mathrm{CV}}^{2}$ values. If the opposite happens then an acceptable QSAR model cannot be obtained for the specific modeling method and data.

Estimation of the predictive ability of a $Q S A R$ model

According to Tropsha [17] the predictive power of a QSAR model can be conveniently estimated by an external $R_{\mathrm{CV} \text {,ext }}^{2}$ (Equation 5).

$$
R_{\mathrm{CV}, \text { ext }}^{2}=1-\frac{\sum_{i=1}^{\text {test }}\left(Y_{\text {exp }}-Y_{\text {pred }}\right)^{2}}{\sum_{i=1}^{\text {test }}\left(Y_{\text {exp }}-\bar{Y}_{\text {tr }}\right)^{2}}
$$

where $\bar{Y}_{\text {tr }}$ is the averaged value for the dependent variable for the training set.

Furthermore Tropsha's research group [17, 18] considered a QSAR model predictive, if the following conditions are satisfied:

$$
\begin{aligned}
& R_{\mathrm{CV}, \text { ext }}^{2}>0.5 \\
& R^{2}>0.6 \\
& \frac{\left(R^{2}-R_{\mathrm{o}}^{2}\right)}{R^{2}}<0.1 \quad \text { or } \frac{\left(R^{2}-R_{\mathrm{o}}^{\prime 2}\right)}{R^{2}}<0.1 \\
& 0.85 \leq k \leq 1.15 \quad \text { or } 0.85 \leq k^{\prime} \leq 1.15
\end{aligned}
$$

Mathematical definitions of $R^{2}{ }_{\mathrm{o}}, R_{\mathrm{o}}^{\prime 2}, k$ and $k^{\prime}$ are based on regression of the observed activities against predicted activities and vice versa (regression of the predicted activities against observed activities). The definitions are presented clearly in Golbraikh et al. [18], but are not repeated here for brevity.

\section{Defining model applicability domain}

The domain of application [17, 19] of a QSAR model must be defined if the model is to be used for screening new compounds. Predictions for only those compounds that fall into this domain may be considered reliable. Extent of Extrapolation [17] is one simple approach to define the applicability of the domain. It is based on the calculation of the leverage $h_{i}$ [20] for each chemical, where the QSAR model is used to predict its activity:

$$
h_{i}=x_{i}^{T}\left(X^{T} X\right) x_{i}
$$

In Equation (10) $x_{i}$ is the descriptor-row vector of the query compound and $X$ is the $k \times n$ matrix containing the $k$ descriptor values for each one of the $n$ training compounds. A leverage value greater than $3 k / n$ is considered large. It means that the predicted response is the result of a substantial extrapolation of the model and may not be reliable.

\section{Results and discussion}

For the selection of the most important descriptors, the aforementioned stepwise multiple regression technique was used. The procedure was automated using a software developed in-house that realizes the ES-SWR algorithm. The seven most significant descriptors according to the ESSWR algorithm are: the Modified Randic index (ChiMod) followed by Lipophilicity (CLogP), Randic Information 4 (ChiInfo4), Repulsion Energy (NRE), Randic Information 3 (ChiInfo3), Randic Information 1 (ChiInfo1) and finally LUMO Energy (LUMO). This selection resulted to the following full linear equation for the prediction of the inhibitory activity $\left(1 / \mathrm{IC}_{50}\right)$ :

$$
\begin{aligned}
\log \left(1 / \mathrm{IC}_{50}\right)= & -0.332 \mathrm{CLogP}+0.226 \mathrm{LUMO} \\
& +0.021^{*} 10^{-3} \mathrm{NRE}+4.22 \mathrm{ChiInfl} \\
& -2.95 \mathrm{ChiInf}-1.30 \text { ChiInf } 4 \\
& +0.058 \mathrm{ChiMod}-2.58 \\
F=32.36 R^{2}= & 0.837 \mathrm{RMSE}=0.298 \\
R_{\mathrm{CV}}^{2} & =0.755 S_{\text {PRESS }}=0.366 \\
n & =52
\end{aligned}
$$


Lipophilicity is known to be important for absorption, permeability, and in vivo distribution of organic compounds [21] and has been used as a physicochemical descriptor in QSARs with great success [22, 23]. Molecular orbital (MO) surfaces visually represent the various stable electron distributions of a molecule. According to the Frontier Orbital Theory, the shapes and symmetries of the highest-occupied and lowest-unoccupied molecular orbitals (HOMO and LUMO) are crucial in predicting the reactivity of a species and the stereochemical and regiochemical outcome of a chemical reaction. All the structures were fully optimized using the AM1 basis set before the calculation of the LUMO Energy $(\mathrm{eV})$. The NRE $(\mathrm{eV})$ contains the energy which is required to keep two electrons, each on separate $\pi$ atoms, from moving apart and the energy which is required to keep two electrons, occupying the same orbital on the same $\pi$ atom, from moving apart. The NRE is more positive as the atom becomes more electronegative. Modified Randic index is based on reciprocal distance of a molecular graph. Randic information topological descriptors (ChiInfol, ChiInfo3, ChiInfo4) are combinations of topostructural and topochemical descriptors [12]. Topostructure indices encode information on the adjacency and distance of atoms in the molecular structure. Topochemical indices quantify information on topology but also specific chemical properties of atoms such their chemical identity and hybridization state. In our recent work Melagraki et al. [24] topological information descriptors were used with great success.

A correlation analysis on the seven selected descriptors (Table 2) was performed to test for internal correlations. All the values deviate from unity considerably so there is no significant corre- lation between the seven independent variables. In order to investigate the possibility of having included outliers in our data set, the extent of the extrapolation method was applied to the 52 compounds that constitute the entire data set. The leverages for all 52 compounds were computed (Table 3) and found to be inside the domain of the model (warning leverage limit 0.461).

The predictive ability of the selected descriptors was further explored, by dividing the full data set consisting of 52 1-(3,3-diphenylpropyl)-piperidinyl phenylacetamides amides into a training set of 39 compounds, and a validation set of 13 compounds. The data set was partitioned in a way that we obtained a representative training set and at the same time a diverse test set in terms of molecular structure [25]. More specifically the selection of the derivatives in the training set was made according to the structure and the scale of the biological action, so that representatives of a wide range of structures (in terms of the different substituents, atoms and action) were included. The distribution of the activity values for the test set follows the distribution of the activity values for the training set. According to Golbraikh and Tropsha [26] this approach is correct since representative points of the test set must be close to those of training set and vice versa.

The compounds that constituted the training and validation sets are clearly presented in Tables 4 and 5, where the 52 compounds are separated in two groups (amides and phenylacetamides). The validation examples are marked with ${ }^{\mathrm{b}}$. The rest of the study will be concentrated on the model which is constructed from the training set. Using the seven selected descriptors, we developed a new MLR equation based on only the 39 training examples:

Table 2. Correlation matrix of the seven selected descriptors.

\begin{tabular}{|c|c|c|c|c|c|c|c|}
\hline & $\mathrm{Clog} \mathrm{P}$ & Lumo & NRE & ChiInfl & ChiInf3 & ChiInf4 & ChiMod \\
\hline $\mathrm{Clog} \mathrm{P}$ & 1 & & & & & & \\
\hline Lumo & -0.09 & 1 & & & & & \\
\hline NRE & 0.13 & -0.29 & 1 & & & & \\
\hline ChiInfl & -0.18 & -0.04 & -0.22 & 1 & & & \\
\hline ChiInf3 & -0.17 & -0.10 & 0.47 & 0.43 & 1 & & \\
\hline ChiInf4 & -0.28 & -0.19 & 0.38 & 0.32 & 0.74 & 1 & \\
\hline ChiMod & 0.11 & 0.002 & -0.70 & 0.18 & -0.53 & -0.45 & 1 \\
\hline
\end{tabular}


Table 3. Leverages for the entire data set.

\begin{tabular}{|c|c|}
\hline Compound Id & Leverages \\
\hline 1 & 0.127 \\
\hline 2 & 0.120 \\
\hline 3 & 0.073 \\
\hline 4 & 0.172 \\
\hline 5 & 0.142 \\
\hline 6 & 0.103 \\
\hline 7 & 0.145 \\
\hline 8 & 0.253 \\
\hline 9 & 0.237 \\
\hline 10 & 0.087 \\
\hline 11 & 0.291 \\
\hline 12 & 0.421 \\
\hline 13 & 0.089 \\
\hline 14 & 0.085 \\
\hline 15 & 0.057 \\
\hline 16 & 0.079 \\
\hline 17 & 0.116 \\
\hline 18 & 0.174 \\
\hline 19 & 0.373 \\
\hline 20 & 0.047 \\
\hline 21 & 0.078 \\
\hline 22 & 0.072 \\
\hline 23 & 0.083 \\
\hline 24 & 0.091 \\
\hline 25 & 0.082 \\
\hline 26 & 0.117 \\
\hline 27 & 0.121 \\
\hline 28 & 0.099 \\
\hline 29 & 0.334 \\
\hline 30 & 0.230 \\
\hline 31 & 0.119 \\
\hline 32 & 0.159 \\
\hline 33 & 0.103 \\
\hline 34 & 0.077 \\
\hline 35 & 0.142 \\
\hline 36 & 0.384 \\
\hline 37 & 0.073 \\
\hline 38 & 0.106 \\
\hline 39 & 0.115 \\
\hline 40 & 0.217 \\
\hline 41 & 0.199 \\
\hline 42 & 0.141 \\
\hline 43 & 0.160 \\
\hline 44 & 0.265 \\
\hline 45 & 0.149 \\
\hline 46 & 0.226 \\
\hline 47 & 0.203 \\
\hline 48 & 0.184 \\
\hline 49 & 0.063 \\
\hline
\end{tabular}

Table 3. Continued.

\begin{tabular}{ll}
\hline Compound Id & Leverages \\
\hline 50 & 0.155 \\
51 & 0.110 \\
52 & 0.149 \\
\hline \multicolumn{1}{l}{$\log \left(1 / \mathrm{IC}_{50}\right)=$} & -0.339 CLogP $+0.262 \mathrm{LUMO}$ \\
& $+0.024^{*} 10^{-3} \mathrm{NRE}+4.21 \mathrm{ChiInfl}$ \\
& $-2.66 \mathrm{ChiInf3}-1.60 \mathrm{ChiInf} 4$ \\
& +0.06 ChiMod -2.81 \\
& \\
$F=17.18 R^{2}=$ & 0.801 RMSE $=0.324$ \\
$R_{\mathrm{CV}}^{2}$ & $=0.657 S_{\text {PRESS }}=0.425$ \\
$n$ & $=39$
\end{tabular}

This equation was used to estimate the CCR5 binding affinities for the training and validation examples resulting in $R^{2}$ statistics equal to 0.801 (as shown above) and 0.921 respectively. The outcomes of the model are presented in the last two columns of Tables 4 and 5. Graphically, observed vs. predicted inhibitory activities for the training and the validation data sets are shown in Figure 1. The results illustrated once more that the linear MLR technique combined with a successful variable selection procedure are adequate to generate an efficient QSAR model for predicting the CCR5 binding affinity of different compounds.

The proposed model (Equation 12) also passed the rest of the tests that we utilized for illustrating its predictive ability (Equations 6-9)

$$
\begin{aligned}
& R_{\mathrm{CV}, \text { ext }}^{2}=0.915>0.5 \\
& R^{2}=0.921>0.6 \\
& \frac{\left(R^{2}-R_{\mathrm{o}}^{2}\right)}{R^{2}}=-0.1787<0.1 \\
& \text { or } \frac{\left(R^{2}-R_{o}^{\prime 2}\right)}{R^{2}}=-0.1595<0.1 \\
& k=1.006 \text { and } k^{\prime}=0.910
\end{aligned}
$$

The model was further validated by applying the $Y$-randomization test. Several random shuffles of the $Y$ vector were performed and the results are shown in Table 6. The low $R^{2}$ and $R_{\mathrm{CV}}^{2}$ values show that the good results in our original model are not due to a chance correlation or structural dependency of the training set. 
Table 4. Binding biological data of amides. training and test data.<smiles>[R]C(=O)N(C)C1CCN(CCC(c2ccccc2)c2ccccc2)CC1</smiles>

\begin{tabular}{|c|c|c|c|c|c|}
\hline & $\mathrm{R}_{2}$ & $\begin{array}{l}\mathrm{IC}_{50}(\mu \mathrm{M}) \\
\text { observed }\end{array}$ & $\begin{array}{c}\log \left(1 / \mathrm{IC}_{50}\right) \\
\text { observed }\end{array}$ & $\begin{array}{l}\text { Training data } \\
\log \left(1 / \mathrm{IC}_{50}\right) \text { predicted }\end{array}$ & $\begin{array}{l}\text { Test data } \\
\log \left(1 / \mathrm{IC}_{50}\right) \text { predicted }\end{array}$ \\
\hline $1^{\mathrm{b}}$ & - & 4.1 & -0.61 & & -0.813 \\
\hline 2 & 4-Pyridinyl & 6.1 & -0.78 & -0.478 & \\
\hline 3 & 4-F- $\mathrm{C}_{6} \mathrm{H}_{4}$ & 7.2 & -0.86 & -0.611 & \\
\hline 4 & 3-NO - -phenyl & 5.1 & -0.71 & -0.066 & \\
\hline $5^{\mathrm{b}}$ & 2-Thienyl & 8.7 & -0.94 & & -0.832 \\
\hline 6 & 2-Furanyl & 7.9 & -0.90 & -0.608 & \\
\hline $7^{\mathrm{b}}$ & Cyclobutyl & 7.4 & -0.87 & & -0.727 \\
\hline 8 & Isobutyl & 3.4 & -0.53 & -0.916 & \\
\hline $9^{\mathrm{b}}$ & Neopentyl & 5.5 & -0.74 & & -0.481 \\
\hline 10 & Benzyl & 0.81 & 0.09 & -0.253 & \\
\hline 11 & & 5.9 & -0.77 & -0.897 & \\
\hline 12 & $N$ & 6.8 & -0.83 & -0.962 & \\
\hline
\end{tabular}

${ }^{\mathrm{b}}$ Test data.

Finally, the extent of extrapolation method was applied to the compounds that constitute the test set. The leverages for all 13 compounds are presented in Table 7. None of the 13 compounds fell outside the domain of the model (warning leverage limit 0.615 ).

The proposed method, due to the high predictive ability [17, 27], can provide a useful aid to the costly and time consuming experiments for determining the CCR 5 binding affinity. The method can also be used to screen existing databases or virtual libraries in order to identify new potentially active compounds. In this case, the applicability domain serves as a valuable tool to filter out "dissimilar" compounds.
Such a group of new derivatives, previously not tested for the specific biological action, was subjected to virtual screening using the produced model (Tables 8-11). The aim was, starting from a primary hit and using both pharmacophore-based and substructure-based modifications to discover a structurally diverse set of potent leads. We have searched for optimized pharmacophore patterns by insertions, substitutions, and deletions of pharmacophoric substituents of the main building block scaffolds. The searching strategy was similar to the one followed in [28]. Finally, we identified the structural trends that lead to improved CCR5 binding affinity. 
Table 5. Binding biological data of phenylacetamides. training and test data.<smiles>[X]c1ccc(CC(=O)N([R2])C2CCN(CCC(c3ccccc3)c3ccccc3)CC2)cc1</smiles>

\begin{tabular}{|c|c|c|c|c|c|c|}
\hline & $\mathrm{R}_{2}$ & $\mathrm{X}$ & $\begin{array}{l}\mathrm{IC}_{50}(\mu \mathrm{M}) \\
\text { observed }\end{array}$ & $\begin{array}{l}\log \left(1 / \mathrm{IC}_{50}\right) \\
\text { observed }\end{array}$ & $\begin{array}{l}\text { Training data } \\
\log \left(1 / \mathrm{IC}_{50}\right) \\
\text { predicted }\end{array}$ & $\begin{array}{l}\text { Test data } \\
\log \left(1 / \mathrm{IC}_{50}\right) \\
\text { predicted }\end{array}$ \\
\hline 13 & $\mathrm{Me}$ & $\mathrm{H}$ & 0.77 & 0.11 & -0.182 & \\
\hline 14 & $\mathrm{Me}$ & $2-\mathrm{Cl}$ & 3.60 & -0.56 & -0.411 & \\
\hline $15^{\mathrm{b}}$ & $\mathrm{Me}$ & $3-\mathrm{Cl}$ & 2.20 & -0.34 & & -0.108 \\
\hline 16 & $\mathrm{Me}$ & $4-\mathrm{Cl}$ & 0.80 & 0.10 & -0.031 & \\
\hline 17 & $\mathrm{Me}$ & 3,4-di-Cl & 0.78 & 0.11 & 0.152 & \\
\hline 18 & $\mathrm{Me}$ & 2,4-di-Cl & 2.60 & -0.41 & -0.289 & \\
\hline 19 & $\mathrm{Me}$ & $2-\mathrm{F}$ & 1.90 & -0.28 & -0.703 & \\
\hline $20^{\mathrm{b}}$ & $\mathrm{Me}$ & $3-\mathrm{F}$ & 1.40 & -0.15 & & -0.042 \\
\hline 21 & $\mathrm{Me}$ & $4-\mathrm{F}$ & 0.66 & 0.18 & 0.031 & \\
\hline 22 & $\mathrm{Me}$ & 3,4-di-F & 0.69 & 0.16 & 0.256 & \\
\hline 23 & $\mathrm{Me}$ & 3-OMe & 0.68 & 0.17 & 0.642 & \\
\hline 24 & $\mathrm{Me}$ & 4-OMe & 0.58 & 0.24 & 0.666 & \\
\hline $25^{\mathrm{b}}$ & $\mathrm{Me}$ & 3,4-di-OMe & 0.65 & 0.19 & & 0.313 \\
\hline 26 & $\mathrm{Me}$ & 3,5-di-OMe & 2.70 & -0.43 & 0.096 & \\
\hline 27 & $\mathrm{Me}$ & 2,4,5-tri-OMe & 1.10 & -0.04 & 0.715 & \\
\hline 28 & $\mathrm{Me}$ & $4-\mathrm{Br}$ & 0.58 & 0.24 & 0.207 & \\
\hline 29 & $\mathrm{Me}$ & 4-Benzyloxy & 3.50 & -0.54 & -0.384 & \\
\hline 30 & $\mathrm{Me}$ & 4-Phenyl & 2.30 & -0.36 & -0.319 & \\
\hline 31 & $\mathrm{Me}$ & $4-\mathrm{CF}_{3}$ & 0.37 & 0.43 & 0.703 & \\
\hline $32^{\mathrm{b}}$ & $\mathrm{Me}$ & $4-\mathrm{OCF}_{3}$ & 0.29 & 0.54 & & 0.901 \\
\hline 33 & $\mathrm{Me}$ & 4-NHCOMe & 0.68 & 0.17 & 0.309 & \\
\hline 34 & $\mathrm{Me}$ & $4-\mathrm{CN}$ & 0.06 & 1.22 & 0.528 & \\
\hline 35 & $\mathrm{Me}$ & $4-\mathrm{SO}_{2} \mathrm{NH}_{2}$ & 0.091 & 1.04 & 0.985 & \\
\hline 36 & $\mathrm{Me}$ & $4-\mathrm{SO}_{2} \mathrm{~N}(\mathrm{Me})_{2}$ & 0.046 & 1.34 & 0.823 & \\
\hline $37^{\mathrm{b}}$ & $\mathrm{Me}$ & 4-SMe & 0.56 & 0.25 & & 0.603 \\
\hline 38 & $\mathrm{Me}$ & $4-\mathrm{CO}_{2} \mathrm{Me}$ & 0.63 & 0.20 & 0.322 & \\
\hline 39 & $\mathrm{Me}$ & $4-\mathrm{OH}$ & 0.47 & 0.33 & 0.335 & \\
\hline 40 & $\mathrm{Me}$ & $4-\mathrm{NO}_{2}$ & 0.15 & 0.82 & 0.734 & \\
\hline 41 & Et & $4-\mathrm{OCF}_{3}$ & 0.31 & 0.51 & 0.066 & \\
\hline 42 & Et & $4-\mathrm{CN}$ & 0.066 & 1.18 & 0.796 & \\
\hline $43^{\mathrm{b}}$ & Et & $4-\mathrm{SO}_{2} \mathrm{NH}_{2}$ & 0.038 & 1.42 & & 1.359 \\
\hline 44 & Et & $4-\mathrm{SO}_{2} \mathrm{~N}(\mathrm{Me})_{2}$ & 0.018 & 1.74 & 1.315 & \\
\hline 45 & Et & $4-\mathrm{SO}_{2} \mathrm{Me}$ & 0.076 & 1.12 & 1.277 & \\
\hline $46^{\mathrm{b}}$ & Et & $4-\mathrm{NO}_{2}$ & 0.11 & 0.96 & & 0.568 \\
\hline 47 & Cyclopropyl & $4-\mathrm{SO}_{2} \mathrm{NH}_{2}$ & 0.033 & 1.48 & 1.305 & \\
\hline
\end{tabular}


Table 5. Continued

\begin{tabular}{lllllll}
\hline & $\mathrm{R}_{2}$ & $\mathrm{X}$ & $\begin{array}{l}\mathrm{IC}_{50}(\mu \mathrm{M}) \\
\text { observed }\end{array}$ & $\begin{array}{l}\log \left(1 / \mathrm{IC} \mathrm{C}_{50}\right) \\
\text { observed }\end{array}$ & $\begin{array}{l}\text { Training data } \\
\log \left(1 / \mathrm{IC} \mathrm{C}_{50}\right) \\
\text { predicted }\end{array}$ & $\begin{array}{l}\text { Test data } \\
\log (1 / \mathrm{IC} \\
\text { predicted }\end{array}$ \\
\hline $48^{\mathrm{b}}$ & Cyclopropyl & $4-\mathrm{SO}_{2} \mathrm{Me}$ & 0.051 & 1.29 & 1.223 \\
49 & Cyclopropyl & $4-\mathrm{NO}_{2}$ & 0.31 & 0.51 & & \\
$50^{\mathrm{b}}$ & Allyl & $4-\mathrm{OCF}_{3}$ & 0.35 & 0.46 & & 0.291 \\
51 & Allyl & $4-\mathrm{SO}_{2} \mathrm{Me}$ & 0.037 & 1.43 & 1.494 & \\
52 & Allyl & $4-\mathrm{NO}_{2}$ & 0.18 & 0.74 & 0.721 & \\
\hline
\end{tabular}

${ }^{\mathrm{b}}$ Test data.

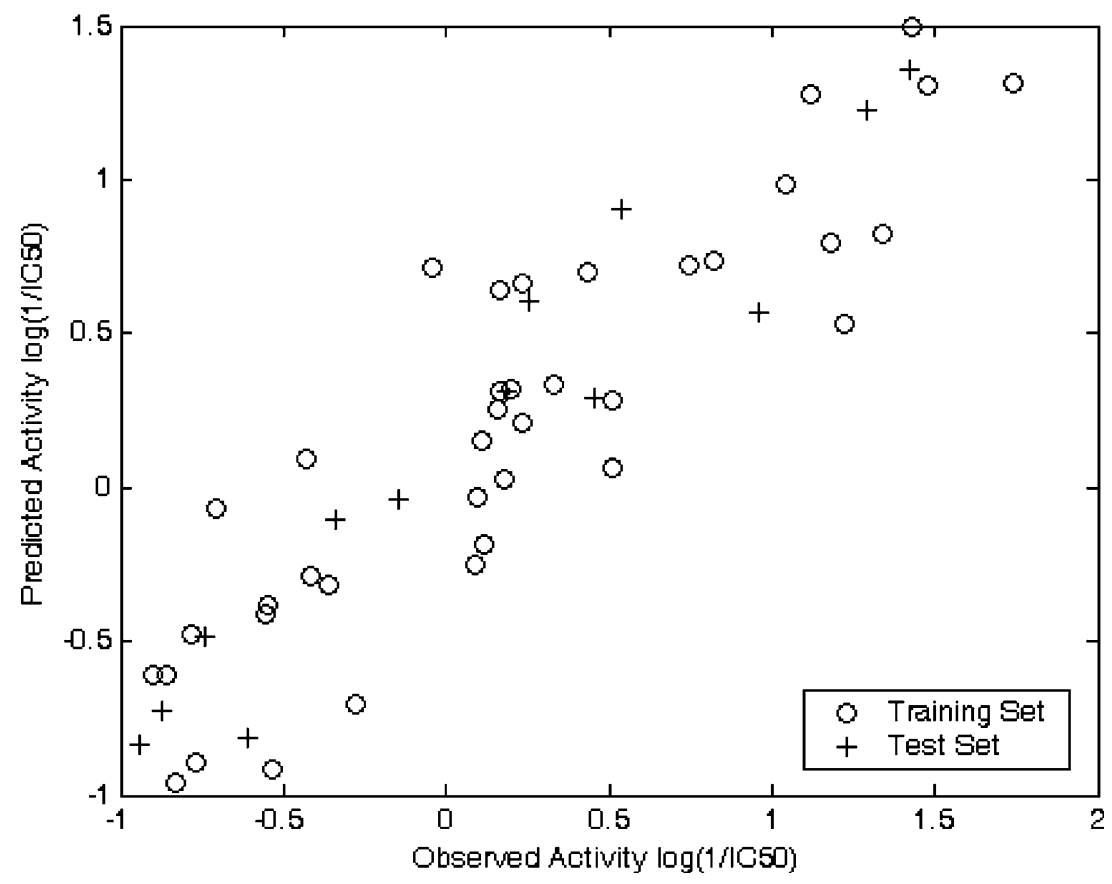

Figure 1 . Observed vs. predicted activity $\log \left(1 / \mathrm{IC}_{50}\right)$ for the training and test set.

Table 6. $R^{2}$ and $R_{\mathrm{CV}}^{2}$ values for several $Y$-randomization tests.

\begin{tabular}{cll}
\hline Iteration & $R^{2}$ & $R^{2} \mathrm{CV}$ \\
\hline 1 & 0.11 & 0.00 \\
2 & 0.16 & 0.00 \\
3 & 0.05 & 0.00 \\
4 & 0.25 & 0.00 \\
5 & 0.06 & 0.00 \\
6 & 0.24 & 0.00 \\
7 & 0.08 & 0.00 \\
8 & 0.18 & 0.00 \\
9 & 0.07 & 0.00 \\
10 & 0.19 & 0.00 \\
\hline
\end{tabular}

Initially alternative functionalities were considered for the acetamide core of the starting $N$-[1-(3,3-diphenylpropyl)piperidin-4-yl]- $N$-methyl2-[4-(methylsulfonyl)-phenyl]acetamide $\quad[\log (1 /$ $\mathrm{IC}_{50}$ ) 0.904] (Table 8). Introduction of a 2-hydroxy guanidine core [id $\left.4 \mathrm{n}, \log \left(1 / \mathrm{IC}_{50}\right) 1.698\right]$ showed significant improvement in the activity and remained within the domain of applicability. This compound id $4 \mathrm{n}$ was therefore chosen for further manipulation. In Table 9 the 4-(methylsulfonyl)phenyl end group of compound id $4 \mathrm{n}$ is replaced with heteroaromatic analogues. With the exception of pyrrole id $19 \mathrm{n}$ all the 5 -membered heteroaromatic systems investigated were outside 
Table 7. Leverages for the test set.

\begin{tabular}{ll}
\hline Compound Id & Leverages \\
\hline 1 & 0.183 \\
5 & 0.195 \\
7 & 0.245 \\
9 & 0.425 \\
15 & 0.079 \\
20 & 0.066 \\
25 & 0.125 \\
32 & 0.247 \\
37 & 0.105 \\
43 & 0.243 \\
46 & 0.385 \\
48 & 0.283 \\
50 & 0.219 \\
\hline
\end{tabular}

of the domain of applicability and as such 5-membered heteroaromatic systems were not considered further. The 6-membered aza heterocycles, pyridine, pyridazine, pyrimidine and pyrazine were investigated. With these systems the methylsulfonyl group showed a preference to be para to the guanidine group and the diaza heterocycles pyrimidin-5-yl [id $14 \mathrm{n}, \log \left(1 / \mathrm{IC}_{50}\right)$ 2.095] and pyrazin-2-yl [id $17 \mathrm{n}, \log \left(1 / \mathrm{IC}_{50}\right) 2.095$ ] gave the best improvements in activity within the domain of applicability. Since the model was unable to differentiate between these two systems we chose only one of them [the pyrazin-2-yl (id 17n)] to proceed with our studies and varied the alkyl group $R^{2}$ on the guanidine core. Increasing the length of the alkyl substituent $R^{2}$ gave improved activity up to $\mathrm{n}-\operatorname{Pr}$ [id $25 \mathrm{n}, \log \left(1 / \mathrm{IC}_{50}\right) 2.389$ ], the $\mathrm{n}-\mathrm{Bu}$ derivative gave reduced activity as did branching on the i-Pr analogue. An investigation of the branched butyl derivatives indicated that the iso- $\mathrm{Bu}$ analogue [id $30 \mathrm{n}, \log \left(1 / \mathrm{IC}_{50}\right)$ 2.524] had superior activity.

Next the piperidine core was replaced by 5membered heterocycles pyrrolidine and pyrrole but in both cases the predicted activity was reduced (Table 10). The alkyl linker between the piperidine core and the diphenylmethane end group was also investigated (Table 10). Extending the alkyl chain by one carbon i.e. propyl $(n=2)$ led to a peak in predicted activity [id $35 \mathrm{n}, \log \left(1 / \mathrm{IC}_{50}\right)$ 2.533 ] but this was improved even further when the end group diphenylmethane was replaced by diphenylamine [id 38n, $\log \left(1 / \mathrm{IC}_{50}\right)$ 2.605]. Further modification to the carbazol led to a reduction in activity (Table 11). Many of the above structures show an increase in activity and fall well within the domain of applicability as such they are worthy of further study. Clearly the model tolerates a wide variety of structural modification demonstrating its potential for virtual screening studies.

Table 8. Virtual screening results. Modification of $N$-[1-(3,3-diphenylpropyl)-piperidin-4-yl]- $N$-methyl-2-[4-(methylsulfonyl)phenyl]acetamide.

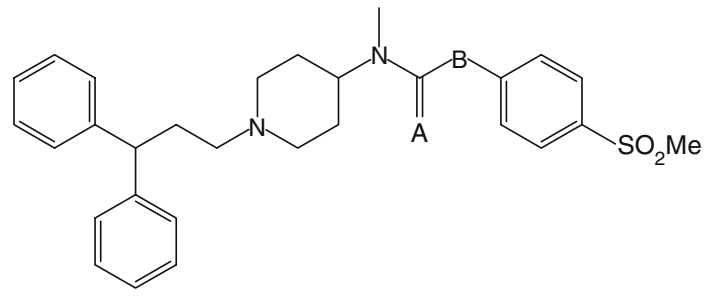

\begin{tabular}{lllll}
\hline $\mathrm{Id}$ & $\mathrm{A}$ & $\mathrm{B}$ & $\log \left(1 / \mathrm{IC}_{50}\right)$ predicted & Leverages \\
\hline $1 \mathrm{n}$ & $\mathrm{O}$ & $\mathrm{CH}_{2}$ & 0.904 & 0.169 \\
$2 \mathrm{n}$ & $\mathrm{S}$ & $\mathrm{CH}_{2}$ & 0.923 & 0.155 \\
$3 \mathrm{n}$ & $\mathrm{NOH}$ & $\mathrm{CH}_{2}$ & 1.042 & 0.105 \\
$4 \mathrm{n}$ & $\mathrm{NH}$ & 1.698 & 0.288 \\
$5 \mathrm{n}$ & $\mathrm{NOH}$ & $\mathrm{O}$ & 1.505 & 0.201 \\
$6 \mathrm{n}$ & $\mathrm{NOH}$ & $\mathrm{S}$ & 1.400 & 0.167 \\
\hline
\end{tabular}

Leverage limit $=0.615$. 
Table 9. Virtual screening results. Modification of 1-[1-(3,3-diphenylpropyl)-piperidin-4-yl]-2-hydroxy-1-alkyl-3-[(methylsulfonyl) heteroaryl]guanidine.<smiles>[R]N(C(=N)N[I-][I-])C1CCN(CCC(c2ccccc2)c2ccccc2)CC1</smiles><smiles>CO[Sb](OC)(OC)c1cccc(C)n1</smiles>

1<smiles>COc1cnc(OS(=O)(=O)OC)cn1</smiles>

7<smiles>CO[SH](C)(=O)c1cc(C)c[nH]1</smiles>

13<smiles>COS(=O)(=O)c1ccc(C)nc1</smiles>

2
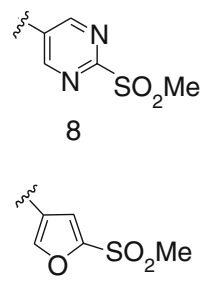

14

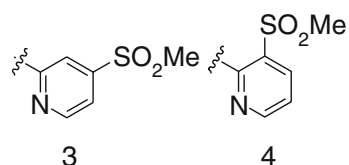<smiles></smiles>

9<smiles>COS(=O)(=O)c1cncc(C)n1</smiles>

10

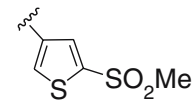

15

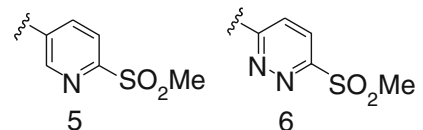<smiles>COS(=O)(=O)c1cnc(C)cn1</smiles>

11<smiles>COc1nccnc1C(C)C</smiles>

\begin{tabular}{rrrll}
\hline Id & HET & $\mathrm{R}_{1}$ & $\log \left(1 / \mathrm{IC}_{50}\right)$ predicted & Leverages \\
\hline $7 \mathrm{n}$ & 1 & $\mathrm{Me}$ & 1.560 & 0.317 \\
$8 \mathrm{n}$ & 2 & $\mathrm{Me}$ & 2.024 & 0.473 \\
$9 \mathrm{n}$ & 3 & $\mathrm{Me}$ & 1.834 & 0.476 \\
$10 \mathrm{n}$ & 4 & $\mathrm{Me}$ & 1.673 & 0.466 \\
$11 \mathrm{n}$ & 5 & $\mathrm{Me}$ & 1.753 & 0.309 \\
$12 \mathrm{n}$ & $\mathrm{Me}$ & 2.395 & 0.760 \\
$13 \mathrm{n}$ & 6 & $\mathrm{Me}$ & 2.366 & 0.734 \\
$14 \mathrm{n}$ & 7 & $\mathrm{Me}$ & 0.512 \\
$15 \mathrm{n}$ & 8 & $\mathrm{Me}$ & 2.095 & 0.506 \\
$16 \mathrm{n}$ & 9 & $\mathrm{Me}$ & 1.747 & 0.515 \\
$17 \mathrm{n}$ & 10 & $\mathrm{Me}$ & 1.905 & 0.512 \\
$18 \mathrm{n}$ & 11 & $\mathrm{Me}$ & 0.095 & 0.505 \\
$19 \mathrm{n}$ & 12 & $\mathrm{Me}$ & 1.744 & 0.407 \\
$2 \mathrm{n}$ & 13 & $\mathrm{Me}$ & 1.722 & 0.926 \\
$21 \mathrm{n}$ & 14 & $\mathrm{Me}$ & 2.513 & 0.841 \\
$2 \mathrm{n}$ & 15 & $\mathrm{Me}$ & 2.571 & 1.179 \\
$23 \mathrm{n}$ & 16 & $\mathrm{Me}$ & 2.682 & 0.908 \\
$24 \mathrm{n}$ & 17 & $\mathrm{Et}$ & 2.607 & 0.519 \\
$25 \mathrm{n}$ & 11 & $\mathrm{Pr}$ & 2.154 & 0.504 \\
$26 \mathrm{n}$ & 11 & $\mathrm{i}-\mathrm{Pr}$ & 2.389 & 0.425 \\
$2 \mathrm{n}$ & 11 & $\mathrm{c}-\mathrm{Pr}$ & 2.281 & 0.770 \\
\hline
\end{tabular}


Table 9. Continued.

\begin{tabular}{lllll}
\hline Id & HET & $\mathrm{R}_{1}$ & $\log \left(1 / \mathrm{IC}_{50}\right)$ predicted & Leverages \\
\hline $28 \mathrm{n}$ & 11 & $\mathrm{n}-\mathrm{Bu}$ & 2.327 & 0.495 \\
$29 \mathrm{n}$ & 11 & sec-Bu & 2.119 & 0.453 \\
$30 \mathrm{n}$ & 11 & $\mathrm{i}-\mathrm{Bu}$ & 2.524 & 0.424 \\
$31 \mathrm{n}$ & 11 & Tert-Bu & 2.026 & 0.664 \\
\hline
\end{tabular}

Leverage limit $=0.615$.

Table 10. Virtual screening results. Modification of 1-[1-(3,3-diphenylpropyl)-piperidin-4-yl]-2-hydroxy-1-isobutyl-3-[5-(methylsulfonyl)pyrazin-2-yl]guanidine.<smiles>COS(=O)(=O)c1ccc(NC(=N)N(CC(C)C)CC(C)C)nc1</smiles><smiles>[Y6]C1CCN(CCN2CCC([Y6])C2)CC1</smiles>

\begin{tabular}{llllll}
\hline Id & HET & $N$ & $\mathrm{Z}$ & $\log \left(1 / \mathrm{IC}_{50}\right)$ predicted & Leverages \\
\hline $32 \mathrm{n}$ & 18 & 1 & $\mathrm{CH}$ & 2.021 & 0.271 \\
$33 \mathrm{n}$ & 19 & 1 & $\mathrm{CH}$ & 2.049 & 0.278 \\
$34 \mathrm{n}$ & 20 & 0 & $\mathrm{CH}$ & 2.412 & 0.397 \\
$35 \mathrm{n}$ & 20 & 2 & $\mathrm{CH}$ & 2.533 & 0.435 \\
$36 \mathrm{n}$ & 20 & 3 & $\mathrm{CH}$ & 2.419 & 0.453 \\
$37 \mathrm{n}$ & 20 & 4 & $\mathrm{CH}$ & 2.264 & 0.539 \\
$38 \mathrm{n}$ & 20 & $\mathrm{~N}$ & 2.605 & 0.466 \\
\hline
\end{tabular}

Leverage limit $=0.615$.

Table 11. Virtual screening results. Investigation of 1-\{1-[3-(9H-carbazol-9-yl)-propyl]piperidin-4-yl\}-2-hydroxy-1-isobutyl-3-[5(methylsulfonyl)pyrazin-2-yl]-guanidine.<smiles>COS(=O)(=O)c1cnc(NC(=N)N(CC(C)C)C2CCN(CCCn3c4ccccc4c4ccccc43)CC2)cn1</smiles>

\begin{tabular}{llr}
\hline Id & $\log \left(1 / \mathrm{IC}_{50}\right)$ predicted & Leverages \\
\hline $39 \mathrm{n}$ & 2.3024 & 0.567 \\
\hline
\end{tabular}

Leverage limit $=0.615$. 


\section{Conclusion}

The successful results of this study led to the conclusion that CCR5 binding affinity can be successfully modeled with physicochemical constants and structural descriptors. The validation procedures utilized in this work (separation of data into independent training and validation sets, $Y$-randomization) illustrated the accuracy and robustness of the produced QSAR model not only by calculating its fitness on sets of training data, but also by testing the predictive ability of the model. The proposed method, due to the high predictive ability, offers a useful alternative to the costly and time consuming experiments for determining CCR5 binding affinity. Furthermore, the produced QSAR model can be used to screen existing databases or virtual libraries in order to identify novel potent compounds. An attempt in this direction was carried out. Synthesis of the molecules proposed by the aforementioned virtual screening procedure and experimental evaluation of their biological activity will show if the method can be used as a general rational drug discovery tool.

\section{Acknowledgements}

A.A. wishes to thank Cyprus Research Promotion Foundation (Grant No. PENEK/ENISX/ 0603/05) for its financial support. A.A and G.M. whish to thank Leventis Foundation for its financial support.

\section{References}

1. Burrows, J.N., Cumming, J.G., Fillery, S.M., Hamlin, G.A., Hudson, J.A., Jackson, R.J., McLaughlin, S. and Shaw, J.S., Bioorg. Med. Chem. Lett., 15 (2005) 25.

2. Kazmierski, W., Bifoulco, N., Yang, H., Boone, L., DeAnda, F., Watson, C. and Kenakin, T., Bioorg. Med. Chem., 11 (2003) 2663.

3. Pipitone, N. and Pitzalis, C., Curr. Opin. Anti-inflammat. Immunomodulat. Invset. Drugs, 2 (2000) 9.

4. Sellebjerg, F., Madsen, H.O., Jensen, C.V., Jensen, J. and Garred, P.J, J. Neuroimmunol., 102 (2000) 98.
5. Fischereder, M., Luckow, B., Wuthrich, R.P., Rothenpieler, U., Schneeberger, H., Panzer, U., Stahl, R.A.K., Hauser, I.A, Budde, K., Neumayer, H.-H., Kramer, B.K., Land, W. and Schlondorff, D., Lancet, 387 (2001) 1758.

6. Andres, P.G., Beck, P.L., Mizoguchi, E., Mizoguchi, A., Bhan, A.K., Dawson, T., Kuziel, W.A., Maeda, N., MacDermott, N., Podolsky, R.P and Reinecker, D.K., J. Immunol., 164 (2000) 6303.

7. Debnath, A.K., J. Med. Chem., 46 (2003) 4501.

8. Xu, Y., Liu, H., Niu, C., Luo, C., Shen, J., Chen, K. and Jiang, H., Bioorg. Med. Chem., 12 (2004) 6193.

9. Song, M., Breneman, C.M. and Sukumar, N., Bioorg. Med. Chem., 12 (2004) 489.

10. Leonard, J.T. and Roy, K., QSAR Comb. Sci., 23 (2004) 387.

11. Roy, K. and Leonard, J.T., J. Chem. Inf. Model., 45 (2005) 1352.

12. Todeschini, R., Consonni, V., Mannhold, R. (Series Editor), Kubinyi, H. (Series Editor) and Timmerman, H. (Series Editor), Handbook of Molecular Descriptors, Wiley-VCH, Weinheim, 2000.

13. Efroymson, M.A., In Ralston, A. and Wilf, H.S. (Eds.), Mathematical Methods for Digital Computers, Wiley, NY, 1960.

14. Efron, B., J. Am. Stat. Assoc., 78 (1983) 316.

15. Osten, D.W., J. Chemom., 2 (1998) 39.

16. Wold, S. and Eriksson, L., In Van de Waterbeemd, H. (Ed.), Chemometrics Methods In Molecular Design, VCH Weinheim, Germany, 1995.

17. Tropsha, A., Gramatica, P. and Gombar, V.K., QSAR Comb. Sci., 22 (2003) 1.

18. Golbraikh, A. and Tropsha, A., J. Mol. Graph. Mod., 20 (2002) 269

19. Shen, M., Beguin, C., Golbraikh, A., Stables, J., Kohn, H. and Tropsha, A., J. Med. Chem., 47 (2004) 2356.

20. Atkinson, A. Plots, Transformations and Regression. Clarendon Press, Oxford (UK), 1985

21. Walters, W.P.A. and Murcko, M.A., Curr. Opin. Chem. Biol., 3 (1999) 384.

22. Devillers, J. (Ed.), Comparative QSAR. Taylor and Francis, Washington, DC, 1998.

23. Hansch, C. and Leo, A. Exploring QSAR: Fundamentals and Applications in Chemistry and Biology. ACS, Washington, DC, 1995.

24. Melagraki, G., Afantitis, A., Sarimveis, H., IgglessiMarkopoulou, O. and Supuran, C.T, Bioorg. Med. Chem., 14 (2006) 1108.

25. Melagraki, G., Afantitis, A., Sarimveis, H., IgglessiMarkopoulou, O. and Alexandridis, A., Mol. Div. (2006) In Press ID AP 11030 20059008.

26. Golbraikh, A. and Tropsha, A., Mol. Div., 5 (2000) 231.

27. Aptula, A.O., Jeliazkova, N.G., Schultz, T.W. and Cronin, M.T.D., QSAR Comb. Sci., 24 (2005) 385.

28. Afantitis, A., Melagraki, G., Sarimveis, H., Koutentis, P.A., Markopoulos, J. and Igglessi-Markopoulou, O., Mol. Div. (2006) In Press DOI MODI28R2. 